Originally published as:

Chmielewicz, B., Goltz, M., Lahrmann, K.-H., Ehlers, B.

Approaching virus safety in xenotransplantation: A search for unrecognized herpesviruses in pigs

(2003) Xenotransplantation, 10 (4), pp. 349-356.

DOI: $10.1034 / \mathrm{j} .1399-3089.2003 .02074 . \mathrm{x}$

The definitive version is available at http://www3.interscience.wiley.com 
Approaching virus safety in xenotransplantation: A search for unrecognized herpesviruses in pigs

Barbara Chmielewicz $^{1}$, Michael Goltz ${ }^{1}$, Karl-Heinz Lahrmann ${ }^{2}$ and Bernhard Ehlers ${ }^{1}$

10

${ }^{1}$ Robert Koch-Institut, Nordufer 20, 13353 Berlin

${ }^{2}$ Freie Universität Berlin, Klinik für Klauentiere, Königsweg 65, 14163 Berlin

Running title: Search for unrecognized porcine herpesviruses 
Authors: Chmielewicz B, Goltz M, Lahrmann KH and Ehlers B

Titel: Approaching virus safety in xenotransplantation: Search for unrecognized herpesviruses in pigs

\section{Journal: XENOTRANSPLANTATION}

\section{Abstract:}

The identification of porcine viruses so far unrecognized is required to minimize virus-related risks associated with xenotransplantation. We used a pan-herpes consensus PCR assay to search for unrecognized porcine species of the Herpesviridae. The assay targets conserved regions of the herpesvirus DNA polymerase (DPOL) gene, using primers that were modified to diminish the assay's recognition capacity for the highly prevalent porcine lymphotropic herpesviruses 1, 2 and 3 (PLHV-1, -2, -3), without substantially lowering the universal detection capacity of the assay. Analysis of 495 porcine blood and tissue samples from 294 animals, including 35 samples from 20 immunosuppressed pigs, resulted in the amplification of 128 herpesviral DPOL sequences. Sequence analysis attributed 127 of the amplimers to the known porcine herpesviruses (PLHV-1, -2, -3; porcine cytomegalovirus; pseudorabiesvirus). In none of the pig samples analysed here, evidence was obtained for the presence of additional novel porcine herpesvirus species. Therefore we conclude that pigs bred for the purpose of xenotransplantation pose a negligible risk of transmitting presently unrecognized herpesviruses to organ recipients.

Keywords: Xenotransplantation, xenozoonosis, porcine herpesviruses, degenerate primers Author for correspondence:

45 Bernhard Ehlers Robert Koch-Institut, Nordufer 20, 13353 Berlin, Germany telephone number: $\quad++49$ / 1888 / 7542347 fax number: $\quad$ + $\quad++49 / 1888 / 7542598$ e-mail: $\quad$ ehlersb@rki.de 


\section{Introduction}

Herpesviruses are known to cause morbidity and mortality in patients who have received allotransplantations. Besides activation of latent infection in the recipient, infections occur particularly through virus transmission from the donor-derived cells or organs. Similarly, in xenotransplantation animal herpesviruses could be transmitted to the xenograft recipient and cause xenozoonotic disease [1]. Beta- and gammaherpesviruses are of particular concern, because they are known to reside latently in lymphocytes and macrophages $[2,3,4]$ which are constituents of all vascularized tissues and organs intended for use in xenotransplantation. Therefore a comprehensive knowledge of the herpesviruses infecting potential donor animals is of great value for safe xenotransplantation. The species currently favoured as a donor of xenografts is the pig $[5,6]$. Remarkably, until recently only two species, one alphaherpesvirus (pseudorabies virus [PRV], suid herpesvirus 1) [7] and one betaherpesvirus (porcine cytomegalovirus [PCMV], suid herpesvirus 2) [8], were known. This changed with the discovery of two closely related gammaherpesviruses in pigs, the porcine lymphotropic herpesviruses 1 and 2 (PLHV-1, PLHV-2) [9,10,11] and, more recently, of a third porcine gammaherpesvirus (PLHV-3) [12]. Having developed detection methods for these viruses, attempts can be started to raise PLHV-free pigs, and to monitor patients undergoing xenotransplantation for inadvertent virus transmission. However, unrecognized herpesviruses would be excluded from these measures and would therefore represent an unassessable risk potential in xenotransplantation.

70 The aim of this study was to search for unknown herpesviruses in porcine blood and tissues. We approached this goal by using a modification of the pan-herpes consensus PCR assay [13]. This assay targets a highly conserved region of the herpesviral DNA polymerase (DPOL) gene with degenerate and deoxyinosine (dI)-substituted primers and was used for the first detection of the PLHVs in porcine spleen and blood samples [9, 12]. However, it could be predicted that the use of this assay would detect PLHVs of any type in many instances, because these herpesvirus species had been found to be highly prevalent in domestic and feral pigs $[9,10,12]$. Therefore, we modified the assay to diminish its recognition potential for the PLHVs, without reducing its universal detection potential substantially. With this modified 
system, a wide collection of porcine blood and tissues, including samples from 80 immunosuppressed pigs, was tested for the presence of previously unrecognised herpesviruses. 


\section{Materials and Methods}

\section{Collection of porcine blood and organ samples and preparation of DNA}

Blood and tissue samples were collected from commercial pig herds, from pigs housed in animal clinics, experimental pigs and wild pigs in Germany, Spain, Sweden, France and the USA. They were kindly provided by Mariano Domingo, Frederik Widen, André Jestin, Carlos Romero, Christene Huang and Clive Patience. Samples from immunosuppressed pigs were obtained at different timepoints (3-21 days) after treatment with dexamethasone on 4 consecutive days (5mg/kg body weight) and kindly provided by Hanns-Joachim Rziha, Bundesforschungsanstalt für Viruskrankheiten der Tiere, Tübingen, Germany. Of the immunosuppressed pigs, 17 animals had been experimentally infected with PRV for other purposes not related to the present study. Here, only PRV-negative or weakly positive samples as judged by PRV-specific PCR were included (29 samples). DNA was prepared and tested for the absence of PCR inhibitors as described previously $[9,10]$.

\section{Pan-herpes consensus PCR}

Consensus PCR was carried out in a nested format with degenerate, dI-containing primers. Three primers were used in first-round PCR (primers DFA, ILK and KG1; Tab. 1) and two primers in second-round PCR (primers TGV and IYG; Tab. 1). PCR reaction mixtures (25 $\mu \mathrm{l})$ contained $1 \mu \mathrm{M}$ of each primer. All other reaction conditions and use of herpesviral DNAs to test the assay performance were as described earlier [13]. 


\section{PLHV-3}

In first-round PCR, instead of using primer KG1, reactions were set up with one of the following mixtures of 8 different modified KG1 primers $\left(K G 1_{a}-K G 1_{h}\right)$. Mixture $K G 1_{b-h}$ was designed to be non-binding to the KG1 primer-binding sequence of PLHV-1 and PLHV-3 and contained the seven primers $K G 1_{b}$ to $K G 1_{h}$ (Tab. 1). Each primer was present at $0.142 \mu \mathrm{M}$ in the reaction mixture. The mixture $\mathrm{KG} 1_{\mathrm{a}, \mathrm{b}, \mathrm{d}-\mathrm{h}}$, designed to be non-binding to the KG1 primer-binding sequence of PLHV-2, was used with the same concentration. PCR reactions with primer mixture $K G 1_{b, d-h}$, designed for non-recognition of all PLHVs, contained $0.166 \mu \mathrm{M}$ of each of the 6 primers (Tab. 1). For second-round PCR a modified sense primer

$115\left(\mathrm{TGV}_{\mathrm{b}}\right)$ was designed to be non-binding to the TGV primer-binding sequence of PLHV-2 (and PLHV-1). It was used at $1 \mu \mathrm{M}$ concentration.

\section{Sequence determination}

The obtained amplimers were purified from remaining primers and dNTPs using Microspin S-300 HR or S-400 HR columns (Amersham Pharmacia Biotech) and sequenced directly using the BigDye terminator chemistry and ABI 377 or $\mathrm{ABI} 3100$ automated sequencers (Applied Biosystems). For 31 samples this was not possible because only faint PCR signals were obtained. Those amplimers were reamplified and cloned using the TOPO TA Cloning Kit (Invitrogen) according to the manufacturer's instructions. The plasmids were extracted using the QIAprep Miniprep Kit (Qiagen) and sequenced. 


\section{Analysis of DNA polymerase sequences}

The design of the modified consensus primers was based on following herpesvirus DNA polymerase sequences:

130 Alphaherpesvirinae: BoHV-1 (Bovine herpesvirus 1, acc.-no. [accession number] Z78205); BoHV-2 (Bovine herpesvirus 2, acc.-no. AF181249); CeHV-15 (Cercopithecine herpesvirus 15, acc.-no. AY037858); CalHV-3 (Callithrichine herpesvirus 3, acc.-no. AF319782); CoHV-1 (Columbid herpesvirus 1, acc.-no. AF141890 and unpublished data from Christian Grund, Bernhard Ehlers and Michael Goltz); EHV-1 (Equine herpesvirus 1, acc.-no. M86664); EHV-4 (Equine herpesvirus 4, acc.-no. AF030027); FeHV (Feline herpesvirus 1, acc.-no. AJ224971); GaHV-2 (Gallid herpesvirus 2 [Marek's disease virus], acc.-no. L40431); HSV-1 (Human herpesvirus 1, acc.-no. X04771); HSV-2 (Human herpesvirus 2, acc.-no. Z86099); PRV (Pseudorabiesvirus = suid herpesvirus 1 [SHV-1], acc.no. L24487); VZV (Varicella-Zoster-virus, acc.-no. X04370).

140 Betaherpesvirinae: CaHV-2 (Callithricheine herpesvirus 2 = Guinea pig cytomegalovirus, acc.-no. L25706); CeHV-8 (Cercopithecine herpesvirus 8 = Rhesus monkey cytomegalovirus, acc.-no. AF033184); CMV (Cytomegalovirus, HHV-5, acc.-no. X17403); ElHV-1 (Elephant herpesvirus 1, acc.-no. AF322977); HHV-6 (Human herpesvirus 6, acc.-no. X83413); HHV-7 (Human herpesvirus 7, acc.-no. U43400); MCMV (Murine cytomegalovirus, acc.-no.

145 U68299); MuHV-2 (Murine herpesvirus 2, acc.-no. U50550); PCMV (Porcine cytomegalovirus, acc.-no. AF268039); TuHV-2 (Tupaia herpesvirus 2, acc.-no. AF074328).

Gammaherpesvirinae: AlHV-1 (Alcelaphine herpesvirus 1, acc.-no. AF005370); BoHV-4 (Bovine herpesvirus 4, acc.-no. AF318573); EBV (Epstein-Barr-virus, acc.-no. X00784); EHV-2 (Equine herpesvirus 2, acc.-no. U20824); HHV-8 (Human herpesvirus 8, acc.-no. U75698); HVS (Herpesvirus saimiri = saimiriine herpesvirus 2 [SaHV-2], acc.-no. X64346); HVA (Herpesvirus ateles = ateline herpesvirus 2 [AtHV-2], acc.-no. AF083424); MHV-68 (murine gammaherpesvirus 68, acc.-no. U97553); PLHV-1 (Porcine lymphotropic herpesvirus 1, acc.-no. AF191042); PLHV-2 (Porcine lymphotropic herpesvirus 2, acc.-no. AF191043); PLHV-3 (Porcine lymphotropic herpesvirus 3, acc.-no. AF494878); RRV

155 (Rhesus monkey rhadinovirus, acc.-no. AF029302). 


\section{Results}

\section{Modification of the consensus PCR for non-recognition of PLHV-1 and -2}

160 A pan-herpes consensus PCR assay was used to search for unknown herpesviruses in pigs. Originally, this assay was set up in a nested format using degenerate primers and could detect more than 20 different herpesvirus DPOL genes [14]. Later, it was carried out with mixtures of degenerate and dI-substituted primers in first- and second-round PCR. This improved the potential of the assay further as shown by detection of novel equine and avian herpesvirus species [13]. In the present study we introduced dI as a „fifth base“ at all 4-fold degenerate primer positions, thereby generating primers which are partially degenerate and partially dIsubstituted. Theoretically, this change in primer design made the system even more versatile, and it simplified the set-up of the assay by reducing the number of primers involved from ten [13] to five (this study). Three of these five primers, designated DFA, ILK (sense) and KG1 (antisense), were used in first-round PCR, primers TGV (sense) and IYG (antisense) in second-round PCR (Tab. 1). A PCR experiment with DNAs of seven different herpesviruses revealed that these degenerate, dI-substituted primers performed like the mixtures of degenerate and dI-substituted primers used previously (data not shown).

Analysis of porcine blood and tissue samples with this PCR system frequently detected PLHV-1, -2 and -3 (data not shown). Therefore, the probability was low to additionally detect an unknown herpesvirus in these samples. To solve this problem, the assay was modified for non-recognition of the PLHVs, without reducing its universal detection potential inadequately. The first-round primer KG1 (26 nt) was replaced by an equimolar mixture of eight modified KG1 primers $\left(K G 1_{a}-K_{G} 1_{h}\right)$ which were not degenerate and not dI-substituted in a stretch of $8 \mathrm{nt}$ at the primers $3^{\prime}$-end (nt 19-26) (Tab. 1). It was presumed that each of these primers alone is responsible for the amplification of those herpesvirus species sharing the same sequence at this stretch of $8 \mathrm{nt}$. Therefore, the omission of one of the modified KG1 primers out of the mixture $\mathrm{KG} 1_{\mathrm{a}-\mathrm{h}}$ (which is the equivalent of the unmodified KG1 primer) should lead to a non-amplification of the corresponding viruses. By leaving primer $K G 1_{\mathrm{a}}$ out 
of the primer mixture $K G 1_{\mathrm{a}-\mathrm{h}}$, mismatches to PLHV-1 and PLHV-3 were introduced (primer mixture $\mathrm{KG}_{\mathrm{b}-\mathrm{h}}$ ). Thus both viruses were theoretically excluded from detection. By leaving primer $\mathrm{KG}_{\mathrm{c}}$ out of the primer mixture $\mathrm{KG} 1_{\mathrm{a}-\mathrm{h}}$, mismatches to PLHV-2 were introduced (primer mixture $K G 1_{\mathrm{a}, \mathrm{b}, \mathrm{d}-\mathrm{h}}$ ). When both primers were left out (primer mixture $\mathrm{KG} 1_{\mathrm{b}, \mathrm{d}-\mathrm{h}}$ ), mismatches to all three PLHVs were inroduced thereby excluding them from detection. In practice, the use of the primer mixtures $K G 1_{b-h}$ or $K G 1_{b, d-h}$ in the consensus PCR indeed abrogated the detection of PLHV-1 and PLHV-3 in porcine blood and tissue samples. However, detection of PLHV-2 was only insufficiently diminished by using the primer mixtures $K G 1_{\mathrm{a}, \mathrm{b}, \mathrm{d}-\mathrm{h}}$ or $\mathrm{KG} 1_{\mathrm{b}, \mathrm{d}-\mathrm{h}}$ (data not shown). The latter result was analysed in more detail by performing the consensus PCR on PLHV-1, PLHV-2 or PLHV-3 with each of the modified KG1 primers as single antisense-primers in the first-round. In the case of PLHV-2, the assumption that a single KG1 primer detects a virus while the others do not proved to be wrong, in contrast to what was found for PLHV-1 and PLHV-3. Up to five out of the eight different modified KG1 primers were able to detect PLHV-2 in samples with high copy numbers (data not shown) thereby explaining the above mentioned insufficient reduction of PLHV-2 detection by the mixtures $K G 1_{\mathrm{a}, \mathrm{b}, \mathrm{d}-\mathrm{h}}$ or $\mathrm{KG} 1_{\mathrm{b}, \mathrm{d}-\mathrm{h}}$.

Because of this reason, we introduced a further change into the assay. The second-round TGV (sense) primer was modified by creating a mismatch with PLHV-2 (and PLHV-1) at position 3 from the $3^{\prime}$-end (primer TGV $\mathrm{b}_{\mathrm{b}}$; Tabs. 1 and 2). The use of the primers DFA, ILK (sense) and the mixture $\mathrm{KG}_{\mathrm{b}, \mathrm{d}-\mathrm{h}}$ (antisense) in first-round PCR, combined with $\mathrm{TGV}_{\mathrm{b}}$ (sense) and IYG (antisense) in second-round PCR, led to a more pronounced reduction but not to a total loss of PLHV-2-detection (compare fig. 1a and fig. 1b, lanes 14-16).

Next, we investigated to what extent the modification of the consensus PCR assay led to a reduction of the universal detection potential. This was first addressed theoretically by aligning the modified KG1 and TGV primers to the KG1- and TGV-primer-binding sites of 30 herpesvirus species (Tab. 2). The primers $K G 1_{b, d-h}$ create with their non-degenerate 3 -portion one or two mismatches with the primer-binding sites of $6 / 30$ viruses (AlHV-1, HVS, HVA, RRV, HHV-7 and BoHV-4). Primer TGV ${ }_{\mathrm{b}}$ creates with its $3^{\prime}$-portion a mismatch with the primer-binding sites of 3/30 viruses (EHV-4, ElHV and again BoHV-4). Thus, 22 out 
of 30 virus species were likely to be detected by the consensus PCR containing all

215 modifications $\left(\mathrm{KG}_{\mathrm{b}, \mathrm{d}-\mathrm{h}}\right.$ plus $\left.\mathrm{TGV}_{\mathrm{b}}\right)$. Of the remaining eight species, seven were probably also detectable, since only either mixture $\mathrm{KG}_{\mathrm{b}, \mathrm{d}-\mathrm{h}}$ or primer $\mathrm{TGV}_{\mathrm{b}}$ (but not both) create mismatches at their 3 '-ends with these species. One species (BoHV-4) was very unlikely to be detected, since both $\mathrm{KG}_{\mathrm{b}, \mathrm{d}-\mathrm{h}}$ and $\mathrm{TGV}_{\mathrm{b}}$ create with their 3'-portions mismatches with BoHV-4 (Tab. 2). This theoretical consideration was experimentally controlled by applying 220 the modified consensus PCR assay to DNAs from eleven different herpesvirus species. Ten DNAs (including EHV-4) were amplified, but BoHV-4 was not (compare fig. 1a and fig. 1b, lanes 2-12). These results confirmed the theoretical data.

Porcine cytomegalovirus (PCMV) was also reported to be highly abundant in pigs as shown by specific PCR $\left[{ }^{15}, 10\right]$. This indicated that the modified consensus PCR required additional changes for non-recognition of PCMV. However, the 3'-portion of the KG1 primer-binding site of PCMV was found to be identical to those of seven other herpesvirus species, mainly alphaherpesviruses (Tab. 2). Therefore, the omission of the primer $K G 1_{f}$ (Tab. 1) from the mixture $K G 1_{b}$, d-h for non-recognition of PCMV was suspected to reduce the universal potential of the assay too much. In addition, we detected PCMV with the unmodified consensus PCR only in samples with high PCMV copy number (not shown). For these reasons we did not expect to detect PCMV with the modified assay in many samples in spite of the high prevalence of PCMV and therefore did not introduce further modifications into the assay.

The potential of the modified consensus PCR to identify herpesviruses present as a minority

235 in double-infected samples was demonstrated with two samples which contained PLHV-1 and PCMV. With the unmodified consensus PCR, PLHV-1 was amplified. With the modified assay using $\mathrm{KG}_{\mathrm{b}, \mathrm{d}-\mathrm{h}}$ and $\mathrm{TGV}_{\mathrm{b}}$, PCMV was amplified (data not shown).

\section{Analysis of porcine tissues with the modified pan-herpes consensus PCR}

The modified consensus PCR was used to examine 495 blood, organ and tissue samples (Tab. 3) selected by two criteria: (i) support of replication and / or latency of herpesviruses 
and (ii) probable use in xenotransplantation. From 268 domestic pigs 437 samples were taken and from 26 feral pigs 58 samples were collected. Among the former, 35 samples were derived from 20 pigs immunosuppressed with dexamethasone. While $83 \%$ of the samples were analysed using all primer modifications $\left(\mathrm{KG}_{\mathrm{b}, \mathrm{d}-\mathrm{h}}\right.$ plus $\left.\mathrm{TGV} \mathrm{b}_{\mathrm{b}}\right), 17 \%$ of the samples were examined in a less stringent way because they had been tested previously for the presence of porcine gammaherpesviruses with PLHV-specific primers (data not shown). For samples which had been tested negative for PLHV-1 and / or PLHV-3 the primer KG1 a was reintroduced to the primer mixture $K G 1_{b, d-h}$, and for samples which had been tested negative for PLHV-2 the primer $K G 1_{c}$ was reintroduced to the primer mixture $K G 1_{b, d-h}$. Thus, the primer mixture for analysis of PLHV-1- and PLHV-3-negative samples $(\mathrm{n}=56)$ was $K G 1_{\mathrm{a}, \mathrm{b}, \mathrm{d}-\mathrm{h}}$, the one for PLHV-2-negative samples $(n=27)$ was $K G 1_{b-h}$. The intention was to keep the detection potential as high as possible.

255 PLHV-1 was found only in 5 samples showing the near perfect abrogation of PLHV-1 detection. PLHV-3 was not detected in any samples. This was not unexpected since with the unmodified assay PLHV-3 is only detected in samples with high PLHV-3 copy number. PLHV-2 was identified in 92 samples, indicating that the modified consensus PCR still had a residual recognition capacity for PLHV-2 in samples with high copy number (Fig. 1). PCMV was amplified from 25 samples, PRV from 5 samples. In addition, one amplimer was obtained from a trigeminal ganglion exhibiting a novel herpesvirus DPOL sequence. Two nested PCR systems were used to search for the putative novel virus in most of the porcine samples listed in Tab. 3, but did not detect the virus in any other samples. From these analyses (data not shown) we concluded that this virus does not naturally infect pigs. 


\section{Discussion}

An extensive search for unrecognized herpesviruses in porcine blood and tissue samples was performed by using a pan-herpes consensus PCR assay which targets the herpesviral DNA polymerase gene with degenerate, dI-substituted primers. This approach had to overcome the abundant presence of the recently discovered porcine gammaherpesviruses PLHV-1, PLHV-2 and PLHV-3 [9, 10, 12], which could mask the possible presence of additional unrecognized herpesviruses and thus most likely could prevent their detection. This difficulty was diminished by modification of the assay in a way which led to an abrogated or lowered detection of the three PLHV species, without reducing the general performance of the assay inadequately (Fig. 1). This modified assay was applied to approximately 500 porcine blood and tissue samples including 35 samples of 20 immunosuppressed pigs. The search in these samples did not result in detection of a so far unrecognized porcine herpesvirus. Although a large quantity of different organs and tissues as well as blood samples were screened, only known porcine viruses were seen.

280 A novel sequence was found in a trigeminal ganglion sample of one pig but could not be detected in other pigs. In a study published separately, we frequently detected this sequence in PBL samples of goats by nested PCR and concluded that the novel sequence originates from a previously unknown caprine gammaherpesvirus (CprHV-2 [16]). Presently, we do not know why we detected CprHV-2 in a pig. It seems probable that the ganglion sample was slightly contaminated with CprHV-2-containing goat material in the section hall, because we detected genomic sequences which are specific for goats in the ganglion sample with a nested PCR (data not shown). On the other hand, it cannot be completely excluded that we detected the goat virus as a consequence of inter-species transmission since this animal was housed at a place where also ruminants are held. Løken et al. [17] described the transmission of ovine herpesvirus-2, the closest relative of CprHV-2, from sheep to pigs. In accordance with this, we may have observed another case of transmission of a ruminant gammaherpesvirus to a pig. In either case, the detection of CprHV-2 is a further indication of the great potential of the pan-herpes consensus PCR. 
Finally, the question arises whether there are still herpesviruses to be discovered in pigs. It is reasonable to assume that an unknown herpesvirus would have been detected by the panherpes consensus PCR if present in sufficient quantity, as we were able to detect more than 40 herpesvirus species with the unmodified assay up till now, a number of them previously unknown $[13,9,16,18]$. For the modified assay it can be assumed that - apart from the few viruses shown to be excluded by the introduced primer modifications - the detection capacity is similar, as shown for a number of herpesvirus species (Fig. 1). It is immanent to the design of the unmodified as well as the modified assay that not every genome is amplified with maximal sensitivity. Therefore, the copy number of a virus genome in a given sample can be of critical importance for successful detection. A non-ubiquituous species may also have remained undetected because certain tissues were only studied in limited numbers. However, herpesviruses are usually not exclusively found in a single tissue or organ. Therefore the large quantity of different organs and tissues, collected also from dexamethasone-treated, immunosuppressed pigs, adds significance to our results. Immunosuppression leads to a reactivation of latent herpesviruses and therefore results in an acute infection, in which the viruses are more easily detectable due to the increased copy numbers. Dexamethasone is well known as a herpesvirus-reactivating drug but causes only a relatively mild immunosuppression [19]. It cannot be completely excluded that there may exist dexamethasone-unresponsive herpesviruses which are only reactivated with stronger immunosuppressive regimens. However, these viruses can only be reactivated when they are already present as a latent infection. Therefore, they principally are accessible to detection by 315 the PCR method used in this study.

It must also be considered that especially PLHV-2 might disturb the detection process if present in larger quantity than a putative unknown virus because PLHV-2 detection could only be diminished but not abrogated by the modifications introduced into the universal PCR assay. Usually, this virus is found with high prevalence only in feral pigs [10]. In this study it was also found in a large quantity of samples from domestic pigs $(\mathrm{n}=79)$. A majority of these samples ( $n=57)$ was derived from only 7 pigs which were housed at the Cattle and Swine Clinic of the 'Freie Universität Berlin'. In this location PLHV-2 was the predominant 
circulating virus at the time blood or necropsy samples were taken, resulting in a high PLHV-2 virus load of samples (data not shown). This explains the frequent detection of PLHV-2 in this study, although only a limited number of wild pig samples was examined. The vast majority of domestic pigs examined $(n=242)$ did not carry PLHV-2 in a higher quantity, and herpesviruses other than PLHV-2 should have been detected in those samples. Finally it must be considered that an unknown virus with the same KG1 and TGV primerbinding sites as PLHV-1 and PLHV-3 might have been undetectable in our search due to the primer modifications of the universal PCR assay. However, the KG1 and TGV primerbinding sites of PLHV-1/-3 are rarely found in other herpesvirus DPOLs (Tab. 2). Therefore, viruses with the same primer-binding sites will be quite closely related to PLHV-1 and PLHV-3. It is likely that pigs infected with such viruses will be recognized by serological assays which detect anti-PLHV antibodies.

335 The arguments discussed above allow us to conclude that (i) additional, unrecognized herpesvirus species are not likely to be present in healthy pigs, that (ii) the herpesvirus status of pigs intended for use as donors in xenotransplantation can be adequately tested by focussing on methods for the detection of PRV, PCMV and the three porcine lymphotropic herpesviruses PLHV-1, PLHV-2 and PLHV-3 and that (iii) animals free of these five virus species pose a negligible risk of inadvertent transmission of herpesviruses during xenotransplantation.

\section{Acknowledgements}

We thank Clive Patience for helpful discussions, Siegfried Pociuli for excellent technical assistance and Ursula Erikli for copy-editing the manuscript. 
Table 2 KG1 and TGV primer-binding sequences of herpesvirus species

Table 3 PCR analysis of porcine samples with modified pan-herpes consensus PCR

Figure 1 Analysis of different herpesvirus DNAs by pan-herpes consensus PCR. Nonmodified (a) or modified (b) pan-herpes consensus PCR was used to amplify DPOL from various purified herpesvirus DNAs (lanes 2-11) and from porcine specimens containing either PLHV-1 (lane 14), PLHV-2 (lane 15) or PLHV-3 (lane 16). SV40 DNA (lane 13 and $\mathrm{H}_{2} \mathrm{O}$ 360 (lane 17) were used as controls. As a marker, pBR322 DNA-Msp I Digest was used (lanes 1 and 16). 


\section{REFERENCES}

${ }^{1}$ CHAPMAN LE, FOLKS TM, SALOMON DR, PATTERSON AP, EGGERMAN, TE, NOGUCHI PD. Xenotransplantation and xenogeneic infections. New Engl J Med 1995: 333: $1498-1501$

${ }^{2}$ SINCLAIR J, SISSONS P. Latent and persistent infections of monocytes and macrophages. Intervirology 1996: 39: 293-301.

${ }^{3}$ FLANO E, HUSAIN SM, SAMPLE JT, WOODLAND DL, BLACKMAN MA. Latent murine gamma-herpesvirus infection is established in activated B cells, dendritic cells, and macrophages. J Immunol 2000: 165: 1074-81.

${ }^{4}$ THORLEY-LAWSON DA, MIYASHITA EM, KHAN G. Epstein-Barr virus and the B cell: that's all it takes. Trends Microbiol 1996: 4: 204-8.

${ }^{5}$ SACHS DH. The pig as xenograft donor. Path Biol 1994:42:217.

${ }^{6}$ FISHMAN JA. Miniature swine as organ donors for man: strategies for prevention of xenotransplant-associated infections. Xenotransplantation 1994: 1: 47-57.

${ }^{7}$ WITTMANN G, RZIHA RJ. Aujeszky's disease (pseudorabies) in pigs. In: Wittmann, G. (ed.), Herpesvirus diseases of cattle, horses and pigs. Kluwer: Boston, 1989.

${ }^{8}$ PLUMMER G. Cytomegaloviruses of man and animals. Prog Med Virol 1973:15: 92-125

${ }^{9}$ EHLERS B, ULRICH S, GOLTZ M. Detection of two novel porcine herpesviruses with high similarity to gammaherpesviruses. J Gen Virol 1999: 80: 971-978.

${ }^{10}$ ULRICH S, GOLTZ M, EHLERS B. Characterization of the DNA polymerase loci of the novel porcine lymphotropic herpesviruses 1 and 2 in domestic and feral pigs. J Gen Virol 1999: 80: 3199-3205.

11 GOLTZ M, ERICSSON T, PATIENCE C, HUANG CA, NOACK S, SACHS DH, EHLERS B. Sequence analysis of the genome of porcine lymphotropic herpesvirus 1 and 
gene expression during post-transplant lymphoproliferative disease of pigs. Virology 2002: 294: 383-393.

${ }^{12}$ CHMIELEWICZ B, GOLTZ M, LAHRMANN KH, FRANZ T, RZIHA J, ROMERO C, EHLERS B, manuscript in preparation.

${ }^{13}$ EHLERS B, BORCHERS K, GRUND C, FRÖLICH K, LUDWIG H, BUHK H.-J. Detection of new DNA polymerase genes of known and potentially novel herpesviruses by PCR with degenerate and deoxyinosine-substituted primers. Virus Genes 1999: 18: 211-220. ${ }^{14}$ VANDEVANTER DR, WARRENER P, BENNETT L, SCHULTZ ER, COULTER S, GARBER RL, ROSE TM. Detection and analysis of diverse herpesviral species by consensus primer PCR. J Clin Microbiol 1996: 34: 1666-1671.

${ }^{15}$ GOLTZ M, WIDEN F, BANKS M, BELÁK S, EHLERS B. Characterization of the DNA polymerase loci of porcine cytomegaloviruses from diverse geographic origins. Virus Genes 2000: 21: 249-255.

${ }^{16}$ CHMIELEWICZ B, GOLTZ M, EHLERS B. Detection and multigenic characterization of a novel gammaherpesvirus in goats. Virus Res 2001:75: 87-94.

17 LØKEN T, ALEKSANDERSEN M, REID H, POW I. Malignant catarrhal fever caused by ovine herpesvirus-2 in pigs in Norway. Vet Rec 1998: 143: 464-467.

18 EHLERS B, BURKHARDT S, GOLTZ M, BERGMANN V, OCHS A, WEILER H, HENTSCHKE J. Genetic and ultrastructural characterization of a European isolate of the fatal endotheliotropic elephant herpesvirus. J Gen Virol 2000: 82: 475-482.

${ }^{19}$ Wittmann G, OHLINGER V, RZIHA H.-J. Occurence and reactivation of latent Aujeszky’s disease virus following challenge in previously vaccinated pigs. Arch Virol 1983: 75: 29-41. 
Table 1 Pan-herpes consensus PCR primers

\begin{tabular}{|c|c|c|c|}
\hline & primary PCR & & \\
\hline $\begin{array}{l}\text { primer } \\
\text { name }\end{array}$ & forward primers & $\begin{array}{l}\text { primer } \\
\text { name }\end{array}$ & backward primers \\
\hline DFA & $5^{\prime}$-gayttygc $\left(n / i^{\$}\right)$ agyyt $(n / i)$ taycc & KG1 & $5^{\prime}-\operatorname{gtcttgctcaccag}(n / i) \operatorname{tc}(n / i) \operatorname{ac}(n / i) c c y t t$ \\
\hline ILK & $5^{\prime}$ - tcctggacaagcagcar $(n / i)$ ysgc $(n / i) m t(n / i) a a$ & KG1a & $5^{\prime}-$ gtcttgctcaccag $(n / i) \operatorname{tc}(n / i) \operatorname{acacctt} t^{\S}$ \\
\hline & & KG1b & $5^{\prime}-\operatorname{gtcttgctcaccag}(n / i) \operatorname{tc}(n / i) \operatorname{acgcctt}$ \\
\hline & & KG1C & $5^{\prime}-$ gtcttgctcaccag $(n / i) \operatorname{tc}(n / i) \operatorname{accccttt}$ \\
\hline & & KG1d & $5^{\prime}-\operatorname{gtcttgctcaccag}(n / i) \operatorname{tc}(n / i) \operatorname{actccttt}$ \\
\hline & & KG1e & $5^{\prime}-\operatorname{gtcttgctcaccag}(n / i) \operatorname{tc}(n / i) \operatorname{acaccctt}$ \\
\hline & & KG1f & $5^{\prime}-\operatorname{gtcttgctcaccag}(n / i) \operatorname{tc}(n / i) \operatorname{acgccctt}$ \\
\hline & & KG1g & $5^{\prime}-$ gtcttgctcaccag $(n / i) \operatorname{tc}(n / i) \operatorname{accccctt}$ \\
\hline & & KG1h & $5^{\prime}-\operatorname{gtcttgctcaccag}(n / i) \operatorname{tc}(n / i) \operatorname{actccctt}$ \\
\hline & secondary PCR & & \\
\hline & forward primers & & backward primer \\
\hline TGV & $\begin{array}{l}5^{\prime}- \\
\text { tgtaactcggtgtaygg }(n / i) \operatorname{ttyac}(n / i) g g(n / i) g t\end{array}$ & IYG & $5^{\prime}$-cacagagtccgtrtc $(n / i) \operatorname{ccrta}(n / i) a t$ \\
\hline TGVa & $5^{\prime}$-tgtaactcggtgtaygg(n/i)ttyac $(n / i) g g t g t$ & & \\
\hline TGVb & $5^{\prime}$-tgtaactcggtgtaygg(n/i)ttyac(n/i)ggvgt & & \\
\hline
\end{tabular}

${ }^{\S}$ The base positions varying between primers KG1a-h and TGVa-b are given in bold 
Table 2 KG1 and TGV primer-binding sequences of herpesvirus species

\begin{tabular}{|c|c|c|}
\hline $\begin{array}{l}\text { primer } \\
\text { name }\end{array}$ & $\begin{array}{l}\text { end of viral primer- } \\
\text { binding site }^{\mathrm{a}}\end{array}$ & virus species $^{\mathrm{b}}$ \\
\hline KG1a & $5^{\prime}-\ldots \operatorname{accttt}-3^{\prime}$ & AlHV-1; HHV-7; HVA; HVS; PLHV-1; PLHV-3 \\
\hline KG1b & $5^{\prime}-\ldots \operatorname{gcctt} t-3^{\prime}$ & BoHV-1; CoHV-1; MCMV; TuHV-1 \\
\hline KG1c & $5^{\prime}-\ldots \operatorname{ccctt} t-3^{\prime}$ & BoHV-4; RRV; PLHV-2 \\
\hline KG1d & $5^{\prime}-\ldots \operatorname{tccttt}-3^{\prime}$ & GaHV-2 \\
\hline KG1e & $5^{\prime}-\ldots \operatorname{accctt}-3^{\prime}$ & FeHV; MHV68 \\
\hline KG1f & $5^{\prime}-\ldots \operatorname{gccctt}-3^{\prime}$ & BoHV-2; CMV; HHV-8; HSV-1; HSV-2; MuHV-2; PCMV; PRV \\
\hline KG1g & $5^{\prime}-\ldots \operatorname{cccctt}-3^{\prime}$ & CaHV-2; EBV; EHV-1; EHV-2; EHV-4; ElHV-1; HHV-6 \\
\hline KG1h & $5^{\prime}-\ldots \operatorname{tccctt}-3^{\prime}$ & CeHV-8; VZV \\
\hline TGVa & $5^{\prime}-\ldots . .9 g \operatorname{tgy}-3^{\prime}$ & BoHV-4; EHV-4; ElHV; PLHV-1; PLHV-2 \\
\hline TGVb & $5^{\prime}-\ldots .9 g v g y-3^{\prime}$ & $\begin{array}{l}\text { AlHV-1; BoHV-1; BoHV-2; CaHV-2; CeHV-8; CMV; CoHV-1; EBV; EHV-1; } \\
\text { EHV-2; FeHV; GaHV-2; HHV-6; HHV-7; HHV-8; HSV-1; HSV-2; HVS; HVA; } \\
\text { MCMV; MHV68; MuHV-2; PCMV; PLHV-3; PRV; RRV; TuHV-1; VZV }\end{array}$ \\
\hline
\end{tabular}

${ }^{\text {a }}$ for the KG1 primers a-h (antisense ) and the TGV primers a-b (sense) the 3 '-ends of the primer binding sites are shown, with the variable base positions in bold. The $5^{\prime}$-portions of the primers are represented by dots. The KG1 sites were complemented and reversed to facilitate comparison with the KG1 primer sequences, listed in tab. 1.

${ }^{\mathrm{b}}$ The origins of the DPOL sequences used in this study are listed in the Methods section. 
Table 3 Analysis of porcine organs with modified pan-herpes consensus PCR

\begin{tabular}{|c|c|c|c|c|c|c|c|}
\hline organ & $\mathrm{N}^{\mathrm{a}}$ & $\mathrm{PLHV}^{\mathrm{b}}{ }^{\mathrm{b}}$ & PLHV-2 & PLHV-3 & PCMV & PRV & negative \\
\hline blood & 155 & - & 7 & - & 4 & 2 & 142 \\
\hline spleen & 54 & 1 & 8 & - & 3 & 1 & 41 \\
\hline lung & 42 & - & 9 & - & 7 & 1 & 25 \\
\hline bone marrow & 35 & - & 9 & - & - & - & 26 \\
\hline kidney & 33 & - & 7 & - & 4 & - & 22 \\
\hline tonsil & 30 & 2 & 7 & - & 1 & - & 20 \\
\hline lymph node & 29 & 1 & 13 & - & 3 & - & 12 \\
\hline liver & 23 & - & 5 & - & 2 & - & 16 \\
\hline bladder & 14 & - & 8 & - & - & - & 6 \\
\hline brain $^{c}$ & 30 & - & 7 & - & 1 & 1 & 21 \\
\hline ganglion trigeminale $^{\mathrm{d}}$ & 10 & - & 4 & - & - & - & 5 \\
\hline thymus & 10 & 1 & 2 & - & - & - & 7 \\
\hline intestine & 6 & - & 4 & - & - & - & 2 \\
\hline pancreas & 5 & - & - & - & - & - & 5 \\
\hline heart & 5 & - & 1 & - & - & - & 4 \\
\hline others $^{\mathrm{e}}$ & 14 & - & 1 & - & - & - & 13 \\
\hline total & 495 & 5 & 92 & - & 25 & 5 & 367 \\
\hline \multicolumn{8}{|c|}{$\begin{array}{l}58 \text { samples were collected from feral pigs (blood, spleen, tonsil, bone marrow and bladder), all others } \\
\text { from domestic pigs of various age and sex including } 5 \text { fetuses. } 35 \text { samples (blood, spleen, tonsil, bone } \\
\text { marrow, lymph nodes, different areas of the brain including trigeminal ganglia) were collected from } 20 \\
\text { pigs immunosuppressed with dexamethasone (see Methods). All samples were analysed with the } \\
\text { modified pan-herpes consensus PCR and amplimers sequenced } \\
\text { b results of sequence analysis of the amplimers listed in columns 3-7. }\end{array}$} \\
\hline \multicolumn{8}{|c|}{ c taken from different areas of the brain (cerebrum, cerebellum, medulla oblongata, bulbus olfactorius) } \\
\hline \multicolumn{8}{|c|}{$\begin{array}{l}\text { din one ganglion a caprine herpesvirus (see Results and Chmielewicz et al., 2001) was detected which } \\
\text { is not indicated in the table }\end{array}$} \\
\hline
\end{tabular}




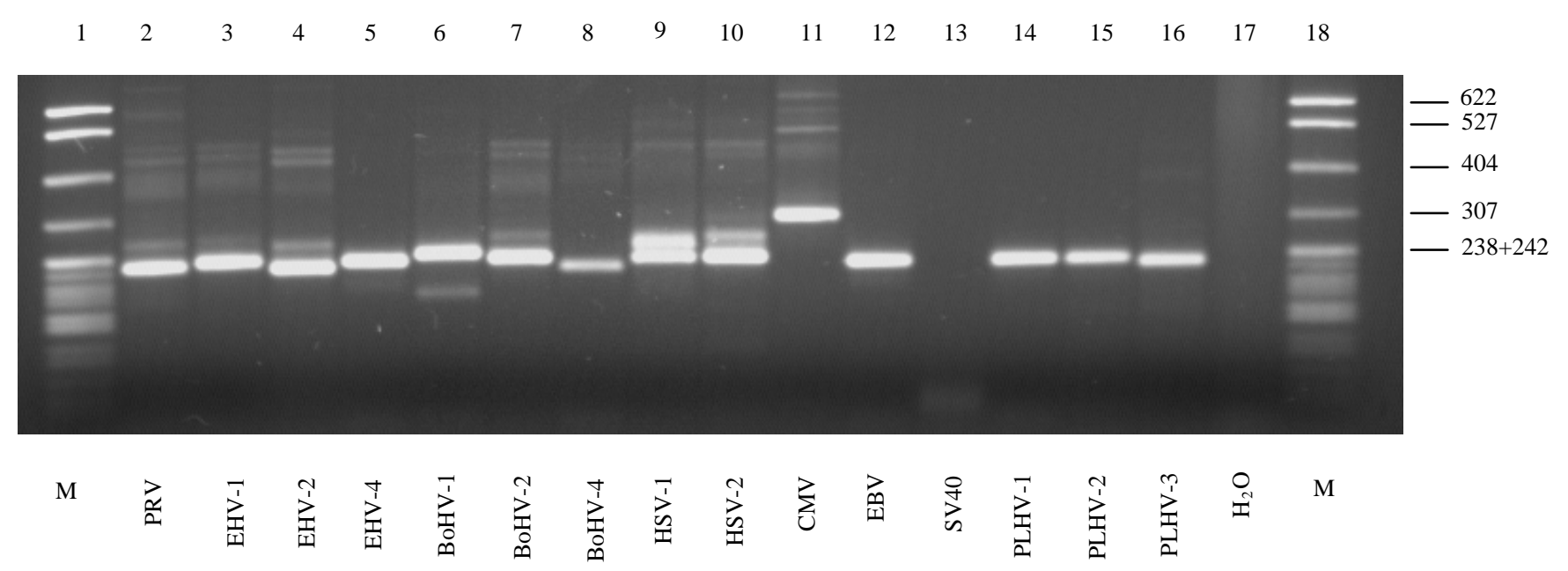

(a)

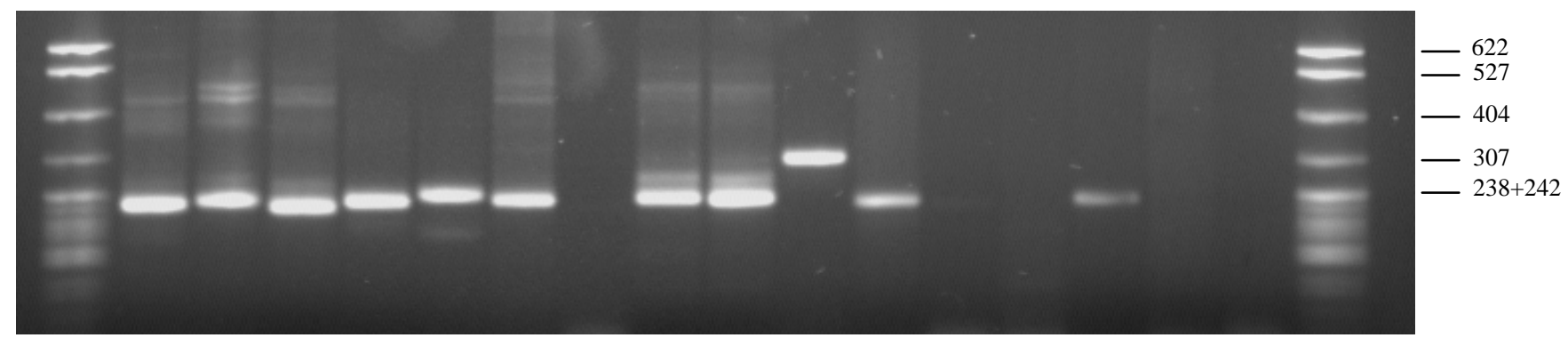

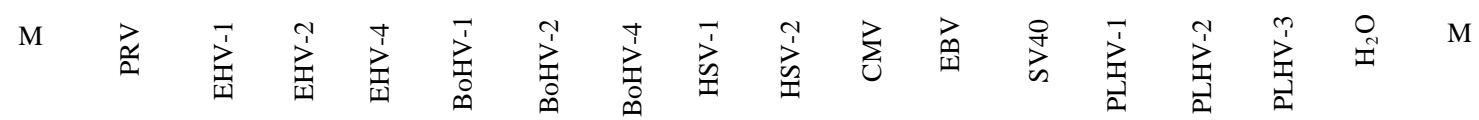

(b) 